\title{
Circular Economy Strategy and Waste Management: A Bibliometric Analysis in Its Contribution To Sustainable Development, Towards A Post COVID- 19 Era
}

\section{Mariana Negrete-Cardoso}

Universidad Popular Autónoma del Estado de Puebla: Universidad Popular Autonoma del Estado de Puebla

Genoveva Rosano-Ortega ( $\sim$ genoveva.rosano@upaep.mx )

Universidad Popular Autonoma del Estado de Puebla https://orcid.org/0000-0002-7297-3456

\section{Erick Leobardo Álvarez-Aros}

Universidad Popular Autónoma del Estado de Puebla: Universidad Popular Autonoma del Estado de Puebla

\section{María Elena Tavera-Cortés Instituto Politécnico Nacional: Instituto Politecnico Nacional}

\section{Carlos Arturo Vega-Lebrún}

Universidad Popular Autónoma del Estado de Puebla: Universidad Popular Autonoma del Estado de Puebla

\section{Francisco Javier Sánchez-Ruíz}

Universidad Popular Autónoma del Estado de Puebla: Universidad Popular Autonoma del Estado de Puebla

\section{Research Article}

Keywords: Circular economy, Waste management, Strategy, COVID-19, Sustainable development, Bibliometric, Environmental Science

Posted Date: June 25th, 2021

DOI: https://doi.org/10.21203/rs.3.rs-629171/v1

License: (c) (1) This work is licensed under a Creative Commons Attribution 4.0 International License. Read Full License 


\section{Abstract}

A descriptive analysis of 416 documents was performed using bibliometric techniques, in order to gather existing knowledge in circular economy (CE) focusing on waste management (2007-2020). The results of this study indicate that annual scientific production increased $94 \%$ in the last five years; highlighting the countries of Italy, Spain, United Kingdom, China, Brazil and India. The conceptual analysis indicates strong linkage between $\mathrm{CE}$ and sustainable production, waste management and recycling. Emerging research trends evolved from processes and industry oriented approach (2017), towards waste management, recycling and circular economy (2019) and sustainable development and urban solid waste (2020). Through intellectual analysis, schools of thought were identified, where the most influential authors such as Wang, Ghisellini, Zhang and the European Commission with the greatest connection with other authors stand out. Results found denote the challenge represented by the implementation of comprehensive policies in $\mathrm{CE}$, in addition to measure its contribution to sustainable development. The above, being a key alternative for green recovery in response to current COVID-19 pandemic.

\section{Introduction}

Over the past decades, Circular Economy (CE) has emerged as a paradigm that promotes more responsible production and consumption patterns. The accelerated global consumption growth of goods has resulted in the overexploitation of natural resources. Thusly, the CE arises in response to the need to dissociate the environmental pressure from economic growth by consolidating a system focused on reduction, reuse, recycle, and recovery of materials in the processes of production, distribution, and consumption.

According to Ellen McArthur Foundation (2020), CE rests on three principles: 1) Preserve and enhance natural capital by controlling finite stocks and balancing renewable resource flows; 2) Optimise resource yields by circulating products, components, and materials at the highest utility at all times in both technical and biological cycles; 3) Foster system effectiveness by revealing and designing out negative externalities.

CE is considered as an umbrella concept looking forward to decreasing material inputs and minimize waste generation (Moraga et al. 2019). Although it is not a new term as it has been addressed since 1960, it is clear that there are still differences upon its conceptualization (Geissdoerfer et al. 2017), characteristics (Ghisellini et al. 2016), definition of its objectives (Morselleto 2019), implementation, and indicators to evaluate its performance (laucovidou et al. 2017a, b; Moraga et al. 2019).

Moreover, its real contribution to sustainable development is constantly questioned (Geissdoerfer et al. 2017) since its objectives have primarily been oriented towards economic prosperity and environmental quality, leaving aside the social equity dimension that must meet the needs of both current and future generations (Kirchher et al. 2017). This gap in knowledge emphasizes the importance of exploring CE 
contribution to sustainable development in the transition from the traditional linear economic model to a circular model, as a strategic alternative for a green reactivation in a post-COVID era.

Currently, the countries belonging to the European Union and China have advanced in the circular model implementation. The latter enacted a specific law on Circular Economy in 2008 while the European Union approved its Action Plan for its exercise in 2015, which proposed a monitoring framework to evaluate the progress towards it (Moraga et al. 2019). These policies contrast significantly with the statements enforced in other countries, especially in the Americas, which highlights its lag to enhance and direct research efforts on its implementation, even when it is an unexplored area.

Therefore, it is timely to take up this concept first addressed by Boulding (1966), who considered that Earth's future would require economic principles that lay in the fact that, under the scheme of a closed economy with limited reservoirs for extraction and contamination, man must meet with a cyclical ecological system capable of producing a continuous input of materials.

Bounding's contribution reveals the need for a fundamental shift in the current economic model towards a perspective that considers the production and consumption stages with a responsible approach, recognizing the impacts of technological cycles of materials, products, and services (Moraga et al. 2019). In this sense, CE notices the circularity of these impacts; however, measuring the progress of the strategies for its implementation is critical to evaluate the overall contribution to sustainable development and green reactivation. Hence, the feasibility of this research in identifying the available information on the evolution of the concept and the existing knowledge regarding its performance, with a focus on waste.

As endorsed by Moraga et al. (2019), CE seeks to lowering material inputs and minimize waste generation. The significance of this premise shows that it directly affects the reduction of natural resources usage and converges on the reuse of waste materials as secondary raw materials. Additionally, $\mathrm{CE}$ attempts to extend the useful life of products and increase their probability for valorization.

Although there are valorization methods aimed at resource recovery from waste (RRfW), these do not consider all value domains (environmental, economic, social, or technical); therefore, partial approaches regarding the complexity of the systems, impacts, trade-offs, and challenges often mislead the observance of the changes that these processes entail towards the CE (lacovidou et al. 2017a). Thereon, examining the experiences of waste optimization and valorization for the transition to the new circular economic model will become a field yet to be explored in future research.

In this context, one of the questions that come up is to know whether is possible to conceive a sustainable production when implying CE. Moreover, can Circular Economy contribute to Sustainable Development as a strategy for green recovery in the post-pandemic era? To understand this concept, its evolution and contribution, a descriptive analysis of the literature was performed using bibliometric techniques, in order to identify the existing knowledge in this field by focusing on waste management from 2007 to 2020 . 
Therefore, this paper aims to contribute to filling the gap in the bibliometric studies related to CE and sustainable development with focus on waste, as an alternative for green recovery in the post-pandemic era. This paper is organized as follows: a) CE overview and its evolution though literature review (Sect. 2); b) methodology presentation (Sect. 3); c) descriptive analysis (Sect. 4.1), comprising the conceptual and intellectual structure (Sect. 4.2); d) final conclusions and further lines of research.

\section{Theoretical Framework And Literature Review}

In recent decades, the overexploitation of natural resources and gradual environmental degradation have become a hot topic on the political agenda as a consequence of the rapid expansion of worldwide resource consumption, which derived from a population growth that has been increasing considerably over the last few years.

According to the sixth edition of the Global Environment Outlook (GEO-6), population pressure and economic development are the main drivers of environmental change, followed by a rapid urbanization and an accelerated technological innovation, which are intimately related to global differentiated models of consumption and production patterns (UN 2019).

In this regard, it is clear that attention must focus on the existent production and consumption patterns in the interest of achieving a change in the current linear economic model, that is uninvolved in carrying capacity and planetary limits issues, towards a new circular model (Pla Julián and Guevara 2019). This concern has already been pointed out by Boulding (1966), who described that the Earth of the future would require economic principles facing a globe with limited reservoirs either for extraction or contamination, in where man had to find his place under a cyclical ecological system capable of providing continuous reproduction of materials. Alternatively stated, Boulding (1966) emphasized at his closed economy, or "spaceman economy" approach, the Earth's capacity to recirculate resources and make them unlimited, principle that has been established as the foundation of the CE.

Following Boulding's research, Peace and Turner (1990) defined for the first time the concept of CE to explain the feasibility of considering the natural environment in the economic flows through the closing of the industrial cycles. Within this framework, development is approached from a sustainable perspective, aimed at exploring the interface between environmental economics, human ecology, and ethics.

The aforementioned paradigm, which is based on sustainability, contemplates three main strands: first, the capacity to inhibit development considering a social cost; second, the regressive potential of the impacts from the developing economy; third, the capacity of providing acceptable levels of environmental quality for present and future generations (Pearce and Turner 1990). Along with Boulding's contribution, the above-mentioned highlights the transcendence of the concept over time.

Over the years, there has been an upsurge on CE researching. Geissdoerfer et al. (2017) analyzed the similarities and differences between CE and sustainability, together with establishing the boundaries and 
relationships among both terms. The former is defined as a regenerative system in which resources, waste, emissions, and energy losses are minimized by slowing and closing product and energy cycles through a durable design, maintenance, reparation, reuse, remanufacturing, reconditioning, or recycling of the arrangement. The second term refers to the balanced unification of the aspects of economic performance, social inclusiveness, and environmental resilience for the benefit of present and future generations.

The results of the analysis revealed that the $\mathrm{CE}$ is a requirement to reach sustainability, which can be disaggregated into distinct types of relationships and sub-relationships to conform an assortment of complementary strategies for managers and decision-makers. Nonetheless, CE still needs to be contrasted with other emerging concepts, such as performance economics, along with its contribution to a forceful sustainability, its influence on supply chains, business models, and innovation systems (Geissdoerfer et al. 2017).

Even though CE has gained ground over the last few years, the concept is still unclear and there is no consensus regarding its definition. Kirchher et al. (2017), through a comprehensive literature review, analyzed a total of 114 definitions; as a result, the findings concluded that the CE is a system replacing the life-cycle concept as a combination of material reduction, reuse, recycling, and recovery during the processes of production, distribution, and consumption at micro (products, companies, consumers), meso (eco industrial parks) and macro (city, region, nation) levels. Therefore, sustainable development, environmental quality, economic prosperity, and social equity are expected to be achieved in order to attain a better future in benefit of present and future generations, enabling new business models and responsible consumers.

As an umbrella concept, the CE sets the limits of its scope; however, its objectives must be defined to achieve the transition from the traditional linear economic model to the desired circular model. Morseletto (2019) systematically examined the targets (new and existing) that facilitate the transition towards a CE; in particular, the study revealed that targets comprising strategies of reuse, repair, refurbishment, and remanufacture extend lifespan of products and their components. Additionally, a set of new targets (remanufacture, refurbish, repair, reuse, reduce, discard, repurpose) are established as powerful governance elements that increase circularity in the economic systems and accelerate the transition towards the new economic model (Morseletto 2019).

Nonetheless, defining CE objectives is not enough to provide a complete display of the concept. Currently, the challenge lies in measuring the performance of its implementation. Moraga et al. (2019) warned of the necessity to set indicators to directly evaluate strategies for preserving functions, products, components, materials, and energy, with a view to highlight the possibilities of exploring new methodologies that consider this set of indicators.

The review of the literature conducted in this paper exhibits the evolution of CE within the years 20072020. Several authors have been focused on defining the concept, analyzing its characteristics, and 
looking for a consensus among the definitions; however, they all converge on the balanced interaction that exists between the economic and environmental systems (Ghisellini et al. 2015).

\subsection{CE strategy}

The strategy towards the CE deals with redirecting the balance of the system to the natural environment, moving from a linear economy to a resource efficient circular one that focuses on the "polluter pays" principle, in which new responsibility schemes are set for producer/consumer relationships, corporations and the environment (Dawson 2019).

Dawson (2019) discussed that CE strategy pursues to achieve the maximum value from resources and lowering waste impacts on the environment; such approach encompasses the circularity of materials and ensures their recycling or disposal whenever is possible. However, its accomplishment depends on policies focused on covering materials lifecycle and extending manufacturers responsibility, with emphasis on consumers. CE strategy seeks to ensure the access to long-lasting sustainable products and consolidate new schemes that assign individual and collective responsibilities.

The transition towards a CE considers not only traditional policies but a change in how waste is disposed following government commitments on waste management. This shift considers a design of products that allows an effective reuse and recycling of materials, oriented to an expansive change from current practices. Nevertheless, it requires implementation and legislative mechanisms to enforce the measures proposed (Dawson 2019).

At present, CE is consolidated as a strategy for a green economic recovery posterior the outbreak of COVID-19 global pandemic disease produced by the SARS-CoV-2 coronavirus, which strongly impacted industrial, commercial, and social activities. Despite social confinement has led to better air quality conditions in several cities around the world (Oleaga et al. 2020) and contributed to SDG 13 "Climate Action", production and consumption dynamics require a shift towards adaptation and resilience in a post-COVID-19 era approaching CE.

The massive generation of sanitary wastes caused by COVID-19 pandemic and the increasing demand of personal protective equipment for healthcare workers have posed a challenge for today's world.

According to Sánchez-Gutiérrez (2021), the large amount of sanitary and plastic waste derived from the pandemic, in addition to the current development model and its production and consumption patterns, demand a more efficient, inclusive, and sustainable post-pandemic waste management system aimed at avoiding adverse effects on health and environment. These illustrate the need to provide a solution regarding waste disposal, for both urban and hazardous waste.

\section{Methodology}

For purposes of understanding the existing knowledge and research related to CE and waste, a descriptive analysis using bibliometric techniques was performed; such techniques allow the quantitative 
analysis of the information gathered from written sources in these two areas.

Bibliometric techniques have been previously applied to identify the most cited researchers, the most mentioned keywords, and the sources from where the documents that best described CE and sustainability concepts were published (Geissdoerfer et al. 2017). Recent studies have adopted these techniques to analyze the evolution of scientific knowledge in the most productive political geographies in the field, such as the European Union and China (Türkeli et al. 2018).

For this paper, literature review consisted at first in the search of information in the SCOPUS database. It is important to underline that first search considered the following keywords and commands in the title: (TITLE ("circular econom*") AND TITLE (solid waste)); however, the search yielded only 21 results. Hence, it was decided to broaden the search by selecting the string (TITLE ("circular econom*") AND TITLE (waste)) in the title. This second search returned 416 results in a .bib and .txt files from 1406 authors, involving a total of 187 sources in a selected 14-year period from 2007 to 2020.

The type of documents examined were mostly articles (263), followed by conference papers (64), conference reviews (1), reviews (47), book Chaps. (17), editorials (12), notes (5), essays (3) and books (2). The analysis was executed with a R-3.6.2 (2019-12-12) software supported by the R Foundation for Statistical Computing, which provides a reliable analysis of the information obtained.

To do so, the zip compressed file, which included the .bib and .txt files, was loaded to perform the analysis of the information by means of tables and graphs that show the relevance of the results. It should be noted that bibliometric studies have increasingly been accepted and bibliometric techniques are being recognized as a systematic approach, in which the content analysis allows an in-depth understanding of the research and the relationships involved (Homrich et al. 2018). Figure 1 describes the process of the information analysis for this research.

As a first stage, the analysis of the information comprised a descriptive analysis in which the aspects of: a) the global annual scientific production, b) the scientific production by country; c) the leading journals regarding the topics of circular economy and waste, and d) the most frequently cited authors were identified. In a second stage, the conceptual and intellectual structure were examined to identify the main research topics and those that have been deepened over the last four years (2017-2020), as well as the author's co-citation networks.

The conceptual structure analysis was developed for identifying the main themes and concepts in which scientific research has been deepened, together with identifying the co-occurrence keywords network. To achieve this aim, the results were filtered out by the most frequently keywords in the articles abstracts. The analysis examined 25 terms. The diameter of the circles represents the keywords frequency in the abstract, that is to say that a largest diameter represents the most researched topics. Additionally, the thickness of the lines represents the strength of the relationship between two topics. 
The intellectual analysis was based on authors co-citation to identify the schools of thought in the academic discourse, namely studies developed by the same author that represent a body of knowledge and related authors whose studies are cited together. For the co-citation network, the parameter of authors co-citation was considered. Twenty-five nodes were selected, which represent the co-citation network of authors appearing together in 25 selected articles from the database. Authors appearing at the center of the co-citation map have stronger linkages with other authors; thus, these are interpreted as the most influential ones.

\section{Results And Discussion \\ 4.1 Descriptive analysis}

The present analysis consists of 416 papers published in the period from 2007 to 2020 . As shown in Fig. 2 , over the past five years the annual scientific production regarding the topics of CE and wastes has risen considerably. Various sources of information were considered, in which the scientific production trend began to emerge since 2016 and grown significantly between 2017 and 2020 .

According to Prieto-Sandoval et al. (2018), the interest of the academic community grown considerably in 2003 after China had started promoting CE. In 2014, CE was included in the European Community Agenda, leading to a significant increase in scientific production during the following six years, mainly in the years of 2019 and 2020, in which 105 and 149 documents were published, respectively.

Even though Prieto-Sandoval et al. (2018) focused on CE and its relationship with the eco-innovation in the period 1969-2016, the findings in this study showed an incremental number of publications, in which $94 \%$ of them were condensed between the years from 2017 to 2020 . This assertion evidences the evolution of scientific production and the progressive interest in $C E$, particularly over the last two years. $A$ greater number of publications is observed in 2020, illustrating that CE theme gained importance, possibly as a consequence of COVID-19 disease declared global pandemic by the World Health Organization in March 2020 (World Health Organization 2020).

The obtained results evolution and scientific production growth over a 14-year period follows a seconddegree polynomial function,

$y=1.7713 x^{2}-17.987 x+33.269 S 1$

in which the $\mathrm{R}^{2}$ value of 0.9215 represents a good fit between the regression line and the observed data.

The equation allows to build up a projection of the number of publications for the years 2030 and 2050 . The former is linked to the year in which the United Nations established as a goal to attain the Sustainable Development Goals and their 169 targets defined in the 2030 Agenda, the new strategy adopted in 2015 aimed to administer the global development programs. The forgoing explains the 
turning point and rise in the number of publications related to sustained economic growth in that year, which implies sustainable production and consumption patterns.

The second of them, the year 2050, denotes the date on which the European Commission sets the target for achieving net-zero greenhouse gas emissions and decoupling economic growth from resource use by 2015 through the European Green Deal, which promotes a modern, resource efficient, and competitive economy (European Commission 2019).

The obtained results denote the interest of the global scientific community to accomplish with the international agreements, such as the 2030 Agenda, mainly the European Community countries facing the COVID-19 health emergency to confront the new waste challenges presented as a result of the pandemic.

On the other hand, the analysis revealed that, from the 416 examined documents, 72 countries have contributed to scientific production in the fields of CE and wastes in the period 2007-2020 (Fig. 3). The countries that stand out being in the top five are: Italy, which is the most productive country with 162 publications, followed by Spain (129), United Kingdom (123), China (115) and Brazil (78).

The analysis centered on the 20 countries with the world's highest scientific production, of which 14 belong to the European Union, representing $70 \%$ of the total. It is worth noting that United Kingdom, even though it no longer belongs to the European Union since 31 January 2020, its contribution places it among the three countries with the highest number of publications.

In contrast, Germany and Japan have been pioneers in promoting CE through detailed policies (Geng et al. 2013). However, the European Union was who approved the action plans for their implementation in 2015 and proposed a monitoring framework (EC 2018).

Additionally, the European Commission launches the European Green Deal for the European Union and its citizens in 2019 as a developing strategy for promoting an equitable and prosperous society, with a modern, resource efficient and competitive economy, in which the goals for achieving net-zero greenhouse gas emissions and decoupling economic growth from resource use are set (European Commission 2019). The aforesaid clarifies the scientific interest of European countries involving this subject.

At present, green economy and decreasing atmospheric pollution rates are consolidated as key points for post-COVID recovery of cities (Pérez 2021). In this context, the European Green Deal emerges as an initiative for post-pandemic green recovery, aimed to promote a rehabilitation route based on a clean and circular economy that involves all its sectors for reaching an efficient use of resources, biodiversity recovery and the reduction of atmospheric pollution (European Commission 2021).

Compared with European countries, in the Americas, Brazil and the United States highlight with a production of 78 and 36 scientific papers, respectively. However, from a sample of 72 countries, Canada (18) and Mexico (13) ranked at the 22nd and 27th place, respectively. To these must be added the efforts 
of Chile (8), Colombia (5), Peru (4), Argentina and Ecuador (3 each), Costa Rica (2) and Bolivia (1). This information coincides with the recently launched C40 Mayors Agenda for a Green and Just Recovery; led by 40 mayors from all over the globe, it defines the steps to be followed to move towards an equitable recovery and a transition to a more sustainable economy in view of the COVID-19 pandemic (C40 cities 2021).

Among the cities joining the green and just recovery from the C40 Mayors Agenda, on the part of Latin America are Bogota, Colombia; Buenos Aires, Argentina; Curitiba, Salvador, Sao Paulo and Rio de Janeiro, Brazil; Guadalajara and Mexico City, Mexico; Lima, Peru; Medellin, Colombia; and Quito, Ecuador. North American cities from United States include Austin, Boston, Chicago, Houston, Los Angeles, Miami, New Orleans, New York, Philadelphia, Phoenix, Portland, San Francisco, Seattle, and Washington DC; while the participating cities from Canada are Montreal, Toronto, and Vancouver.

The aforesaid underlines the countries interest to encourage $C E$ as an alternative for lowering material inputs, minimize waste generation, and decouple the use of natural resources from economic growth as the path for an equitable, green, and prosperous recovery towards a post-pandemic era. Nonetheless, results delineate the gaps that still exist between developed and developing countries in the subject.

The systematic review of literature emphasizes the academic interest of both countries and leading journals on CE and waste understandings with reference to the highest number of published papers (Table 1). Among these, the following stand out: Journal of Cleaner Production with 43 published articles; Resources, Conservation and Recycling (26) and Sustainability (Switzerland) (20). The journal Environmental Science and Pollution Research got the 13th position out of a universe of 20 journals, comprising five published articles and 47 citations.

The results coincide with the findings reported by Prieto-Sandoval et al. (2018) who, when attempting to establish a consensus of the CE concept, conducted a systematic literature review of leading journals, including the Journal of Cleaner Production, Journal of Industrial Chemistry, Resources, Conservation and Recycling, Journal of Environmental Technology and Journal of Sustainability.

It must be underlined that, although the research carried out by Prieto-Sandoval et al. (2018) is focused on eco-innovation, this paper analysis has approach on the topic of waste. Despite that, both analyses put in the first positions the leading journals in CE: Journal of Cleaner Production (Netherlands); Resources, Conservation and Recycling (Netherlands); and Sustainability (Switzerland); which revolve around the disciplines of business, management, accounting, economics, energy, sustainability, environmental sciences, politics, and law. 
Table 1

Top 15 journals with the highest number of published articles on CE and waste (2007-2020)

\begin{tabular}{|lllll|}
\hline No. & Source & Articles & $\begin{array}{l}\text { H- } \\
\text { Index }\end{array}$ & $\begin{array}{l}\text { Total } \\
\text { Citations }\end{array}$ \\
\hline 1 & Journal of Cleaner Production & 43 & 16 & 1134 \\
\hline 2 & Resources Conservation and Recycling & 26 & 12 & 539 \\
\hline 3 & Sustainability (Switzerland) & 20 & 9 & 246 \\
\hline 4 & Science of the Total Environment & 18 & 9 & 202 \\
\hline 5 & Waste Management & 18 & 8 & 212 \\
\hline 6 & Waste Management and Research & 10 & 5 & 78 \\
\hline 7 & Bioresource Technology & 9 & 7 & 381 \\
\hline 9 & Environmental Engineering and Management Journal & 7 & 1 & 15 \\
\hline 10 & E3s Web of Conferences & 6 & 2 & 7 \\
\hline 11 & Energies & 6 & 2 & 9 \\
\hline 12 & Renewable and Sustainable Energy Reviews & 6 & 1 & 6 \\
\hline 13 & Environmental Science and Pollution Research & 6 & 4 & 63 \\
\hline 14 & $\begin{array}{l}\text { International Multidisciplinary Scientific Geoconference } \\
\text { Surveying Geology and Mining Ecology Management Sgem }\end{array}$ & 5 & 4 & 47 \\
\hline 15 & Acs Sustainable Chemistry and Engineering & 4 & 2 & 24 \\
\hline Source: Own elaboration based on Scopus database. & 5 & & \\
\hline & & 5 & & \\
\hline
\end{tabular}

On the contrary, the most frequently cited papers considered to have the greatest impact in the field of study were identified. Out of a total of 416 examined documents from 187 sources and 1406 authors, the 10 most cited papers were selected (Table 2). 
Table 2

Most cited documents in the subject of CE and waste

\begin{tabular}{|lllll|}
\hline Paper & Year & Source & $\begin{array}{l}\text { Total } \\
\text { Citations }\end{array}$ & $\begin{array}{c}\text { TC per } \\
\text { Year }\end{array}$ \\
\hline Pan S-Y & 2015 & Journal of Cleaner Production & 223 & 32 \\
\hline $\begin{array}{l}\text { Malinauskaite } \\
\text { J }\end{array}$ & 2017 & Energy & 218 & 44 \\
\hline Nizami As & 2017 & Bioresource Technology & 168 & 34 \\
\hline Lacy P & 2016 & $\begin{array}{l}\text { Waste to Wealth: The Circular Economy } \\
\text { Advant }\end{array}$ & 161 & 27 \\
\hline Singh J & 2016 & Journal of Cleaner Production & 146 & 24 \\
\hline Hu J & 2011 & Journal of Cleaner Production & 141 & 13 \\
\hline Haupt M & 2017 & Journal of Industrial Ecology & 99 & 20 \\
\hline Huysman S & 2017 & Resources Conservation and Recycling & 98 & 20 \\
\hline Tisserant A & 2017 & Journal of Industrial Ecology & 97 & 19 \\
\hline Liguori R & 2016 & Bioresource Technology & 93 & \\
\hline Source: Own elaboration based on Scopus database. & & 16 \\
\hline
\end{tabular}

The paper "Strategies on implementation of waste to energy (WTE) supply chain for circular economy system: a review" by Pan et al. (2015) had 223 citations in 2015. This document illustrates a portfolio of options for waste-to-energy technologies, such as combustion, gasification, and anaerobic digestion, for the purpose of achieving CE systems.

Alternatively, the study conducted by de Malinauskaite et al. (2017) performs a general review of the national systems for municipal waste management and the reconversion of waste into energy, under the perspective of $\mathrm{CE}$ in European countries. The authors recognize the calorific value of MSW, which implies its use as a "waste-to-energy" energy source, and its conversion into energy as a key factor to reach a CE that maintains the value of products, materials, and resources to market for as long as possible, minimizing waste and resource use. Given that CE is in the lead of the EU Agenda, Malinauskaite et al. (2017) concede that all UE Member States should transit to a smarter waste treatment with focus on CE approach in the context of waste policies.

Such paper examines EU policies implementation. Since WtE is traditionally linked to MSW management and organization, its approach considers the identification of distinct municipal waste management practices of the selected countries and their focus for adopting $\mathrm{CE}$, as well as the extent to which WtE technologies have played any role in this matter. 
In the third place, the paper "Waste biorefineries: enabling circular economies in developing countries" by Nizami et al. (2017) stands out with a total of 168 citations. This document highlights waste biorefineries as a choice for achieving CE in developing countries, where waste is valued as an encouraging energy source, that is to say as value-added products.

Once again, waste usage and energy generation from waste are among the most cited documents worldwide; thus, CE is placed as a solution to waste generation and emissions. The study performed by Loizia et al. (2018) stresses the relevance of implementing the CE model in food waste concerns, in which globally 1.3 billion t/year of foods are disposed of in landfills and contribute with 3.5-4.2 billion ton of $\mathrm{CO}_{2}$ equivalent. This paper is centered on the $\mathrm{CE}$ concept and the optimization and improvement of biogas production from an up-flow anaerobic sludge blanket reactor using food waste and natural minerals. The results lead to expect to use food waste in the existing anaerobic treatment plants, proposing a selective collection at source of this waste, its deviation from landfills and use as a secondary resource for energy recovery through a conversion towards a CE.

The aforementioned documents denote the importance of waste recovery, optimal use, reduction, and the need to implement waste treatment policies aimed to achieve a CE. In this sense, CE strategy defines its objectives towards the elimination, prevention, reuse, and recycling of materials, which must be achieved by 2030 .

\subsection{Conceptual and intellectual structure}

The second analysis was focused on the conceptual structure through which the main themes and concepts were determined and deepened in the scientific research, achieving the identification of the network of keywords co-occurrence.

The search was accomplished through the filtering of results by the keywords that were most frequently presented in the abstract of the articles; a total of 25 terms were examined, from which the most relevant concepts (5) were: economy, circular, waste, management, and environment (Fig. 4).

The diameter of the circles represents the keywords frequency in the abstract, in which a largest diameter means the most researched topics; in this instance, the words economy, circular, waste, management, and environment were the most repeated keywords. At the same time, the thickness of the lines connecting the circles represents the strength of the relationship between two topics, as it is with the concepts of economy and circular, which are mightily linked, and these in turn with the topics of waste and management. The aforesaid due to the strong relationship between the reduction of waste generation and the cyclical use of resources.

From the strong relationship between circular economy and waste, the concepts of management, environmental, production, development, sustainable, and recycling are linked. The issue of waste production and management is a critical point when considering the implementation of CE policies, which are focused on promoting a shift in the production and consumption patterns, as proposed in the Sustainable Development Goal 12 of the 2030 Agenda (UN 2015). 
This Goal aims to ensure sustainable consumption and production patterns, related to an efficient use of energy and resources, decrease environmental impact of the construction of infrastructure, improve access to basic services, and create green jobs, apart from generating greater profits derived from economic activities by reducing the use of resources, environmental degradation, and pollution. Simultaneously, people's quality of life is improved through a systematic approach involving the cooperation of all the members of the supply chain (UN 2015). The relationship between CE and the production and management of wastes is strongly linked, as shown in Fig. 2, pointing that conceiving CE is not possible without considering a sustainable production that contributes to sustainable development.

The conceptual structure analysis also reveals a powerful linkage between CE and waste. According to Moraga et al. (2019), in their analysis of indicators to evaluate CE performance, it was found that most CE indicators from literature are focused on the preservation of materials, primarily on recycling, which is another of the most frequently found concepts. Although CE promotes recycling, it is not the only action to be considered. This evinces the need to explore various strategies, not only related to the preservation of materials but their functions, products, components, and energy, as stated by Moraga et al. (2019).

In addition, an analysis was conducted to determine the topics that have been trending over the last four years, considering the period of 2017-2020. It was observed that the main research topics have been fluctuating over time, including their frequency. In 2019, the topic of waste management was addressed more frequently (221), followed by recycling (190) and CE (168); whereas in 2020, the most trending topics were sustainable development and municipal solid waste (Table 3 ).

Table 3

Main research topics in the period of 2017-2020

\begin{tabular}{|llll|}
\hline $\mathbf{2 0 1 7}$ & $\mathbf{2 0 1 8}$ & $\mathbf{2 0 1 9}$ & $\mathbf{2 0 2 0}$ \\
\hline Food industry (9) & Solid wastes (19) & $\begin{array}{l}\text { Waste management } \\
(221)\end{array}$ & $\begin{array}{l}\text { Sustainable development } \\
(76)\end{array}$ \\
\hline Processes (7) & $\begin{array}{l}\text { Industrial Ecology } \\
(16)\end{array}$ & $\begin{array}{l}\text { Recycling (190) } \\
\text { Developing } \\
\text { countries (7) }\end{array}$ & $\begin{array}{l}\text { Municipal solid waste } \\
(68)\end{array}$ \\
\hline Resource use (6) & Risk assessment (9) & $\begin{array}{l}\text { Circular Economy } \\
(168)\end{array}$ & Solid waste (60) \\
\hline Source: Own elaboration based on Scopus database. & Economic aspects (52) \\
\hline
\end{tabular}

The focus over the last years has been towards an integral insight, in which an evolution in the research of municipal solid waste and sustainable development towards a waste treatment policy have been noticed. This integral insight considered solid wastes and industrial ecology in 2018, whereas in 2019 it 
trended towards recycling and waste management. In the same year, the topic of CE was a spotlight among the research topics, while in 2020 the most frequent topics focused on sustainable development and municipal solid waste.

On the other hand, though the intellectual analysis, it was possible to identify schools of thought in the academic discourse. According to Beyhan and Cetindamar (2011), studies conducted by the same author constitute a body of knowledge and the authors who have related documents are cited together; thereby, authors network of co-citation is established.

Figure 5 shows 25 co-citation nodes representing the network of authors appearing together in the 25 selected articles from the database. Ghisellini, Wang, Zhang and the European Commission appear in the co-citation map as the authors with highest linkage to other authors, followed by Geissdoerfer and Kircherr, who are interpreted as the most influential authors.

The study performed by Ghisellini et al. (2016) is a baseline reference on CE, covering two decades of research in the literature review. The paper highlights its main characteristics and perspectives (origins, basic principles, advantages, disadvantages, models, and implementation at different global levels), hence its importance and co-citation frequency.

In contrast, Wang Y. excels for his contributions to the e-waste field, covering the ecological and health risk assessment for the spatial distribution of heavy metals in a CE park for e-wastes. His contribution contemplates the quantification of spatial flows of e-waste in China's informal sector, the implications of China's foreign waste ban on global CE, and the industrial symbiosis to achieve a CE through value-added materials reached through the design in the automobile industry (Han et al. 2018).

The work of Zhang et al. (2019) contributes to the waste issue and the need for considering the management of waste as a vision towards a CE with a zero-waste approach. Their analysis on the waste management barriers in China reveals the absence of regulatory pressures, environmental education, market pressures and demands to a smart waste management.

Conversely, the study performed by Geissdoerfer et al. (2017) is a baseline as it proposes CE as a new paradigm of sustainability that questions the relationship between both concepts, which is still unclear in the literature. The bibliometric analysis and snowballing techniques applied, served to establish the state of the art regarding $C E$ and to identify the similarities, differences and relationships between $C E$ and sustainability.

It must be noted that both Ghisellini's and Geissdoerfer's contributions have a central position on the map of sources of knowledge produced in the literature of European Union countries; the former was generated in Italy and Sweden, in collaboration with China, and the latter between United Kingdom and the Netherlands.

The European Commission highlights among the most co-cited authors. It is to be underlined that EU countries have a more advanced path in CE since the approval of their action plan for its implementation 
in 2015 and the application of their monitoring framework; thus, member countries of the European Union have had significant contributions to the knowledge production on the subject.

\section{Conclusions}

Currently, CE represents a strategy for achieving a green economic recovery in the face of the COVID-19 pandemic and climate crisis, contributing to the development of more sustainable cites. In this sense, this paper analyzes the evolution of the CE concept and its bestow to sustainable development, with emphasis on waste as a strategy for green reactivation in a post-COVID era.

The annual scientific production regarding CE has increased over the last five years, reaching a significant growth between 2019 and 2020. Speaking of European countries, their progress is related to the incorporation of CE into the European Community Agenda (Prieto-Sandoval et al. 2018), the development of the action plan for its implementation, and the application a monitoring framework (Moraga et al. 2019). Conversely, the turning point and upturn in the number of publications in 2015 agree with the endorsement of the Agenda 2030 in this same year and the scientific community interest in contributing to the international agreements towards a sustainable development. The rise of publications in 2019, denotes the commitment of European countries to promote the decoupling of economic growth from natural resources, in response to the COVID health emergency through the European Green Deal, as well as the release of the C40 Mayors' Agenda in the face of the need for an equitable recovery and a transition to a more sustainable economy in front of the COVID-19 pandemic. Nevertheless, the results connote the existent gaps between developed and developing countries.

Amongst the leading journals on the topic of CE and waste, the following stand out: Journal of Cleaner Production; Resources, Conservation and Recycling; and the Journal of Sustainability. Once again, European countries are at the head with the highest number of articles published on CE and waste. It was observed that within the papers with highest impact, that is to say the most frequently cited works globally, the papers of Pan et al. (2015), Malinauskaite et al. (2017), and Nizami et al. (2017) are highlighted as they relate waste use and energy production from waste, including the need to execute waste treatment policies towards a transition to $\mathrm{CE}$.

The co-occurrence network is highlighted in the analysis of the conceptual structure, where the most frequent words found in the abstracts were: economy, circular, waste, management, and environment. Furthermore, the analysis reveals the strength in which the circular economy is related with waste management, being not only a relevant but a pertinent topic in which scientific research has deepened over recent years; therefore, it is relevant to observe that it is not possible to conceive a CE model without a production contributing to sustainable development, such as established in SDG 12 of the 2030 Agenda. According to Moraga et al. (2019), the focus should not only be on the preservation of materials, such as recycling, but also on functions, products, components, and energy.

The evolution in trending research topics over the last four years discloses a leap in 2019 from waste treatment to a waste management tending to recycling and CE, reaching a comprehensive vision in 2020 , 
where the main research topics focused on municipal solid wastes and sustainable development. This paradigm shift resulting from the environmental degradation, which is linked to the prevailing linear economic development (Prieto-Sandoval et al. 2017), stresses not only the need for industries to move towards a more responsible consumption and production models, but challenge governments to enforce comprehensive policies on CE and municipal solid wastes aimed at decreasing carbon footprint and improve environmental quality.

Finally, in the intellectual analysis, the schools of thought were identified, in which the European Commission and the authors Ghisellini et al. (2016), Zhang et al. (2019) and Geissdoerfer et al. (2017) were underlined as those with the greatest influence and linkage with other authors. The European Commission stands out as the most co-cited because of the advantage of European countries in the field of CE. Ghisellini et al. (2016) become a baseline of the characteristics and perspectives concerning CE, whereas Geissdoerfer et al. (2017) define the state of the art of CE as a new sustainability paradigm. On the other hand, Zhang et al. (2019) identify the barriers to waste management, which are the lack of regulatory pressures, environmental education, culture, market pressures and demands to a smart waste management.

Concretely, in the context of the COVID-19 pandemic, the change in consumer behavior and social lifestyle produced impacts on the circularity of the supply chain, mainly due to the large amounts of single-use products in the food, health, and plastic industries. Therefore, it becomes evident to apply methods and tools, such as life-cycle assessments, and promote resilient systems during the COVID-19 pandemic to lead to sustainable production and consumption (Tseng et al. 2020).

The COVID-19 pandemic can serve as a constructive change driver for sustainability and future resilience, but also as a challenge for adopting CE strategies in face of a scenario with accelerated municipal and hazardous waste generation rates (Wuyts et al. 2020). The results of the present study illustrate the challenges of implementing comprehensive CE policies in a post-COVID-19 era and the need to measure its progress, contribution to sustainable development and to the economic reactivation and green recovery.

Hence, the importance for developing future lines of research focused on decoupling economic growth from resource use, that contribute to an efficient use of resources towards a clean and circular economy, an integral evaluation of the contribution of circular economy to sustainable development, a legal framework that promotes $\mathrm{CE}$ and update waste management regulations.

The scope of this paper was limited to the search of information in Scopus database and some articles from Google Scholar. Therefore, it is suggested to include for future research other databases, such as Web of Science, as well as to broaden the search by considering the keywords "circular econom*" and "waste valorization", or "solid waste" and "hazardous waste"; the last two in attention to the waste derived from the pandemic. 


\section{Declarations}

Acknowledgements

This work has been sponsored by the Consejo Nacional de Ciencia y Tecnología (CONACyT) in the framework of the doctoral scholarship to conduct the postgraduate studies in Strategic Planning and Technology Management over the period 2020-2024.

\section{Ethics approval and consent to participate}

Not applicable

\section{Consent for publication}

Not applicable

\section{Availability of data and materials}

The datasets used and/or analysed during the current study are available from the corresponding author on reasonable request.

\section{Competing interests}

"The authors declare that they have no competing interests"

\section{Funding}

Departamento de Investigaciones, Universidad Popular Autónoma del Estado de Puebla

\section{Authors' contributions}

All authors contributed to the study conception and design.

Conceptualization: [Mariana Negrete Cardoso], [Genoveva Rosano Ortega];

Methodology: [Erick Leobardo Álvarez Aros],[Mariana Negrete Cardoso];

Formal analysis and investigation: [Mariana Negrete Cardoso]; [Francisco Javier]

Writing - original draft preparation: [Mariana Negrete Cardoso];

Resources: [Erick Leobardo Álvarez Aros];

Writting, Review and Editing: [Mariana Negrete Cardoso], [Erick Leobardo Álvarez Aros], [Genoveva Rosano Ortega]; [María Elena Tavera]; [Carlos Arturo Vega Lebrun],

All authors read and approved the final manuscript. 
Authors' information (optional)

MNC Circular Economy and Strategic Planning

GRO Environmental Impact

ELAA Strategic Planning

CAVL Sustainable Business Management

METC Sustainable Development

FJSR Sustainable Development

\section{References}

1. Beyhan B, Cetindamar D (2011) No escape from the dominant theories: The analysis of intellectual pillars of technology management in developing countries. Technological Forecasting and Social Change, 78(1), 103-115. https://doi:10.1016/j.techfore.2010.10.001

2. Boulding KE (1966) The economics of the coming spaceship earth. http://www.ub.edu/prometheus21/articulos/obsprometheus/BOULDING.pdf.

3. C40 Cities (2021, March 5) C40 Mayors' Agenda for a green and just recovery. https://www.c40.org/other/agenda-for-a-green-and-just-recovery

4. Dawson L (2019) Our Waste, our Resources; A Strategy for England - Switching to a circular economy through the use of extended producer responsibility. Environmental Law Review, 21(3), 210218. https://doi.org/10.1177/1461452919851943

5. Ellen Macarthur Foundation (2015) Towards a circular economy: Business rationale for an accelerated transition. https://www.ellenmacarthurfoundation.org

6. EC (2018) Measuring progress towards circular economy in the European Union - Key indicators for a monitoring framework. SWD (2018) 17 Final. European Commission, Strasbourg. https://ec.europa.eu/environment/circular-economy/pdf/monitoring-framework_staff-workingdocument.pdf

7. European Commission (2019) Communication from the Commission to the European Parliament, the European Council, the Council, the European Economic and Social Committee and the Committee of the Regions. The European Green Deal. COM (2019) 640 final. Bruselas. https://eurlex.europa.eu/resource.html?uri=cellar:b828d165-1c22-11ea-8c1f01aa75ed71a1.0004.02/DOC_1\&format=PDF

8. European Commission (2021, March 5) European Green Deal. https://ec.europa.eu/info/strategy/priorities-2019-2024/european-green-deal_es\#acciones

9. Geissdoerfer M. Savaget P, Bocken NM, Hultink EJ (2017) The Circular Economy-A new sustainability paradigm? Journal of Cleaner Production, 143, 757-768. 
https://doi.org/10.1016/j.clepro.2016.12.048

10. Geng, Y, Sarkis J, Ulgiati S, Zhang P (2013) Measuring China's Circular Economy. Science, 339(6127), 1526-1527. https://doi:10.1126/science.1227059

11. Ghisellini P, Cialani C, Ulgiati S (2016) A review on circular economy: the expected transition to a balanced interplay of environmental and economic systems. Journal of Cleaner production, 114, 1132. https://doi.org/10.1016/j.jclepro.2015.09.007

12. Han W, Gao G, Geng J, Li Y, Wang Y (2018) Ecological and health risks assessment and spatial distribution of residual heavy metals in the soil of an e-waste circular economy park in Tianjin, China. Chemosphere, 197, 325-335. https://doi.org/10.1016/j.chemosphere.2018.01.043

13. Homrich AS, Galvao G, Abadia LG, Carvalho MM (2018) The circular economy umbrella: Trends and gaps on integrating pathways. Journal of Cleaner Production, 175, 525-543. https://doi.org/10.1016/j.jclepro.2017.11.064

14. Hu J, Xiao Z, Zhou R, Deng W, Wang M, Ma S (2011) Ecological utilization of leather tannery waste with circular economy model. Journal of Cleaner Production, 19(2-3), 221-228. https://doi:10.1016/j.jclepro.2010.09.018

15. Iacovidou E, Velis CA, Purnell P, Zwirner O, Brown A, Hahladakis J, Millward-Hopkins J, Williams PT (2017a) Metrics for optimising the multi-dimensional value of resources recovered from waste in a circular economy: A critical review. Journal of Cleaner Production, 166, 910-938. https://doi.org/10.1016/j.jclepro.2017.07.100

16. lacovidou E, Millward-Hopkins J, Busch J, Purnell P, Velis CA, Hahladakis JN, Zwirner O, Brown A (2017b) A pathway to circular economy: Developing a conceptual framework for complex value assessment of resources recovered from waste. Journal of Cleaner Production, 168, 1279-1288. https://doi.org/10.1016/j.jclepro.2017.09.002

17. Kirchherr J, Reike D, Hekkert M (2017) Conceptualizing the circular economy: An analysis of 114 definitions. Resources, conservation and recycling, 127, 221-232.

https://doi.org/10.1016/resconrec.2017.09.005

18. Loizia P, Neofytou N, Zorpas AA (2018) The concept of circular economy strategy in food waste management for the optimization of energy production through anaerobic digestion. Environmental Science and Pollution Research, (), - . https://doi.org/10.1007/s11356-018-3519-4

19. Malinauskaite J, Jouhara H, Czajczyńska D, Stanchev P, Katsou E, Rostkowsk P, Thorne RJ, Colón J, Ponsá S, Al-Mansour F, Anguilano L, Krzyżyńska R, López IC, Vlasopoulos A, Spencer N (2017) Municipal Solid Waste Management and Waste-to-Energy in the Context of a Circular Economy and Energy Recycling in Europe. Energy, 0, S0360544217319862-. https://doi.org/10.1016/j.energy.2017.11.128

20. Moraga G, Huysveld S, Mathieux F, Blengini GA, Alaerts L, Van Acker K, Dewulf J (2019) Circular economy indicators: What do they measure? Resources, Conservation and Recycling, 146, 452-461. https://doi.org/10.1016/j.resconrec.2019.03.045 
21. Morseletto P (2019) Targets for a circular economy. Resources, Conservation and Recycling. https://doi.org/10.1016/j.resconrec.2019.104553

22. Nizami AS, Rehan M, Waqas M, Naqvi M, Ouda O K., Shahzad K, Miandad R, Khan MZ, Syamsiro M, Ismail IMI, Pant D (2017) Waste biorefineries: Enabling circular economies in developing countries. Bioresource Technology, 241, 1101-1117. https://doi:10.1016/j.biortech.2017.05.097

23. Oleaga M, Lorenz U, Rodríguez A (2020) Los ODS: Clave Para La Recuperación De La Covid-19. Instituto Vasco de Competitividad - Fundación Deusto. Cuadernos Orkestra, núm. 75/2020. ISSN 2340-7638. https://doi.org/10.13140/RG.2.2.17230.89925 (in Spanish)

24. Pan SY, Du M.A, Huang IT, Liu IH, Chang EE, Chiang PC (2015) Strategies on implementation of waste-to-energy (WTE) supply chain for circular economy system: a review. Journal of Cleaner Production, 108, 409-421. https://doi.org/10.1016/j.jclepro.2015.06.124

25. Pearce DW, Turner RK (1990) Economics of natural resources and the environment, New York, London, Harvester Wheatsheaf.

26. Pérez AMR (2021) Air and Covid-19: What can we learn from pandemic times for a more sustainable recovery of cities? Retrieved from: https://territoriossostenibles.com/calidad-del-aire/aire-y-covid-19que-podemos-aprender-de-los-tiempos-de-pandemia-para-una-recuperacion-mas-sostenible-de-lasciudades (in Spanish)

27. Pla-Julián I, Guevara S (2019) Is circular economy the key to transitioning towards sustainable development? Challenges from the perspective of care ethics. Futures, 105, 67-77. https://doi.org/10.1016/j.futures.2018.09.001

28. Prieto-Sandoval V, Jaca C, Ormazabal M (2018) Towards a consensus on the circular economy. Journal of Cleaner Production, 179, 605-615. https://doi.org/10.1016/J.Jclepro.2017.12.224

29. Sánchez-Gutierrez FO (2021) Post-pandemic challenges in solid waste management. CienciAmérica: Revista de divulgación científica de la Universidad Tecnológica Indoamérica, ISSN-e 1390-9592, 10(1), 11-23.

30. Türkeli S, Kemp R, Huang B, Bleischwitz R, Mcdowall W (2018) Circular economy scientific knowledge in the European Union and China: A bibliometric, network and survey analysis (20062016). Journal of cleaner production, 197, 1244-1261. https://doi.org/10.1016/j.jclepro.2018.06.118

31. Tseng ML, Ardaniah V, Bui TD, Ali MH, Chiu AS (2020) Circular Economy Needs the Resilient Systems in COVID-19 Pandemic. Jurnal Pengurusan (UKM Journal of Management), 59.

32. UN (2015) Transforming our world: The 2030 agenda for sustainable development. New York: United Nations General Assembly, 11-12 August.

33. United Nations Environment Program (2015) Sustainable consumption and production: A handbook for policy makers. https://sustainabledevelopment.un.org

34. UN Environment (2019) Global Environment Outlook - GEO-6: Summary for Policymakers. Nairobi. http://doi.org/10.1017/9781108639217 
35. World Health Organization (27 $7^{\text {th }}$ april 2020) Archived: WHO Timeline - COVID-19. News. https://www.who.int/news/item/27-04-2020-who-timeline--covid-19

36. Wuyts W, Marin J, Brusselaers J, Vrancken K (2020) Circular Economy as a COVID-19 Cure? Resources, Conservation \& Recycling. https://doi.org/10.1016/j.resconrec.2020.105016

37. Zhang A, Venkatesh VG, Liu Y, Wan M, Qu T, Huisingh D (2019) Barriers to smart waste management for a circular economy in China. Journal of Cleaner Production. https://doi.org/10.1016/j.jclepro.2019.118198

\section{Figures}

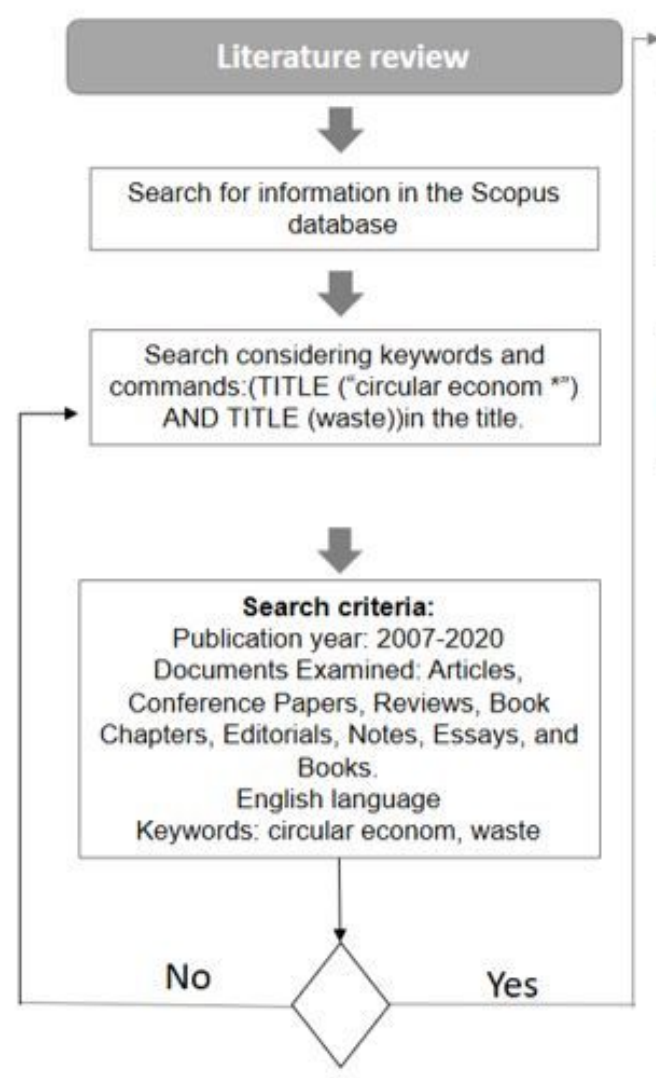

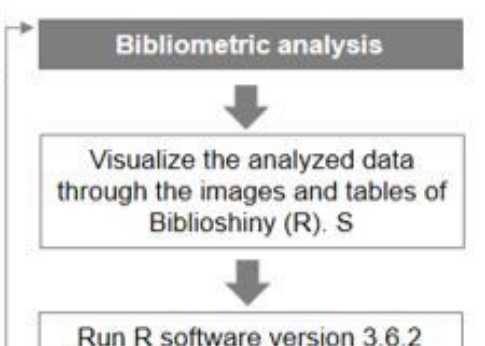

Run R software version 3.6.2 (2019-12-12), The R Foundation for Statistical Computing; upload the file to Biblioshiny.

\section{Figure 1}

Literature review and analysis process Source: Own elaboration 


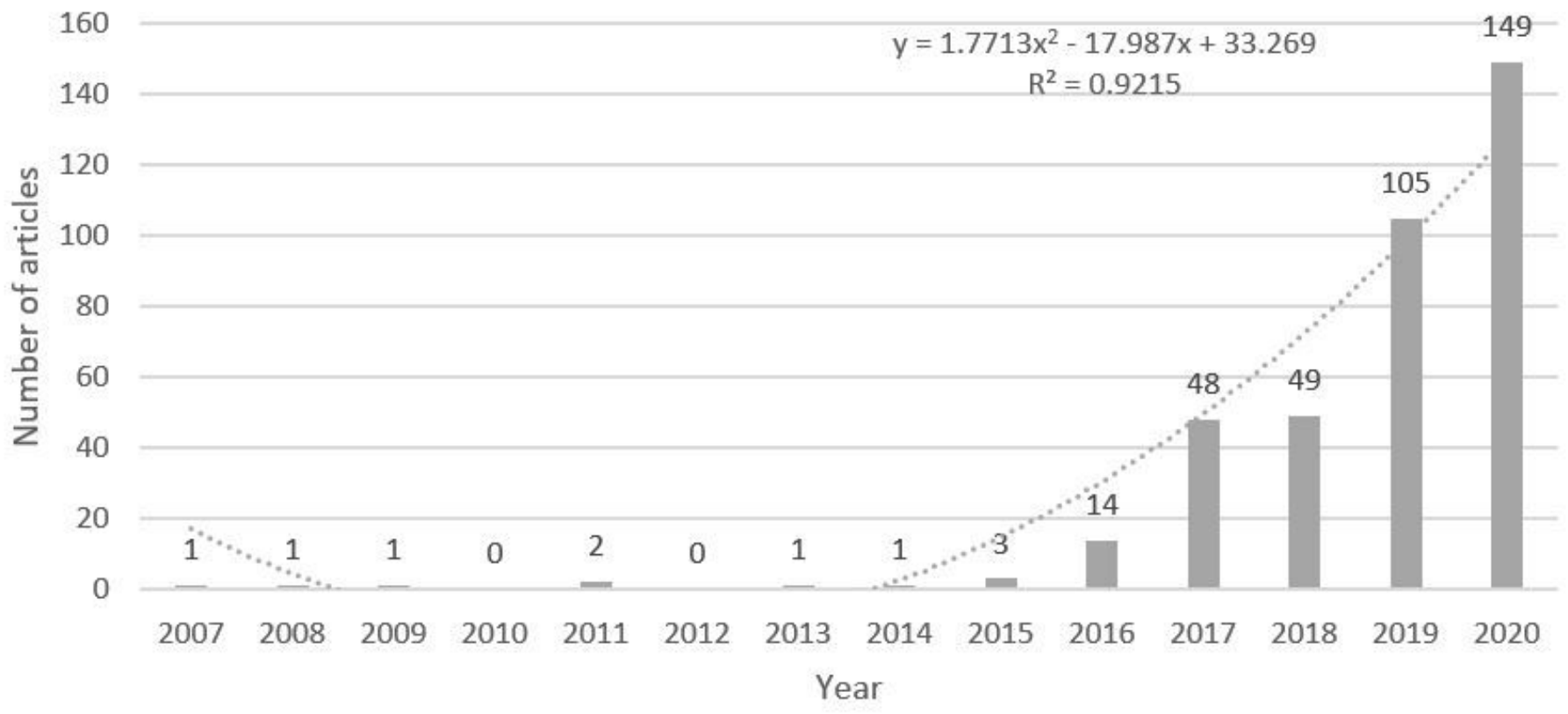

Figure 2

Evolution of published articles on Circular Economy and waste over the period 2007-2020 Source: Own elaboration based on Scopus database. 

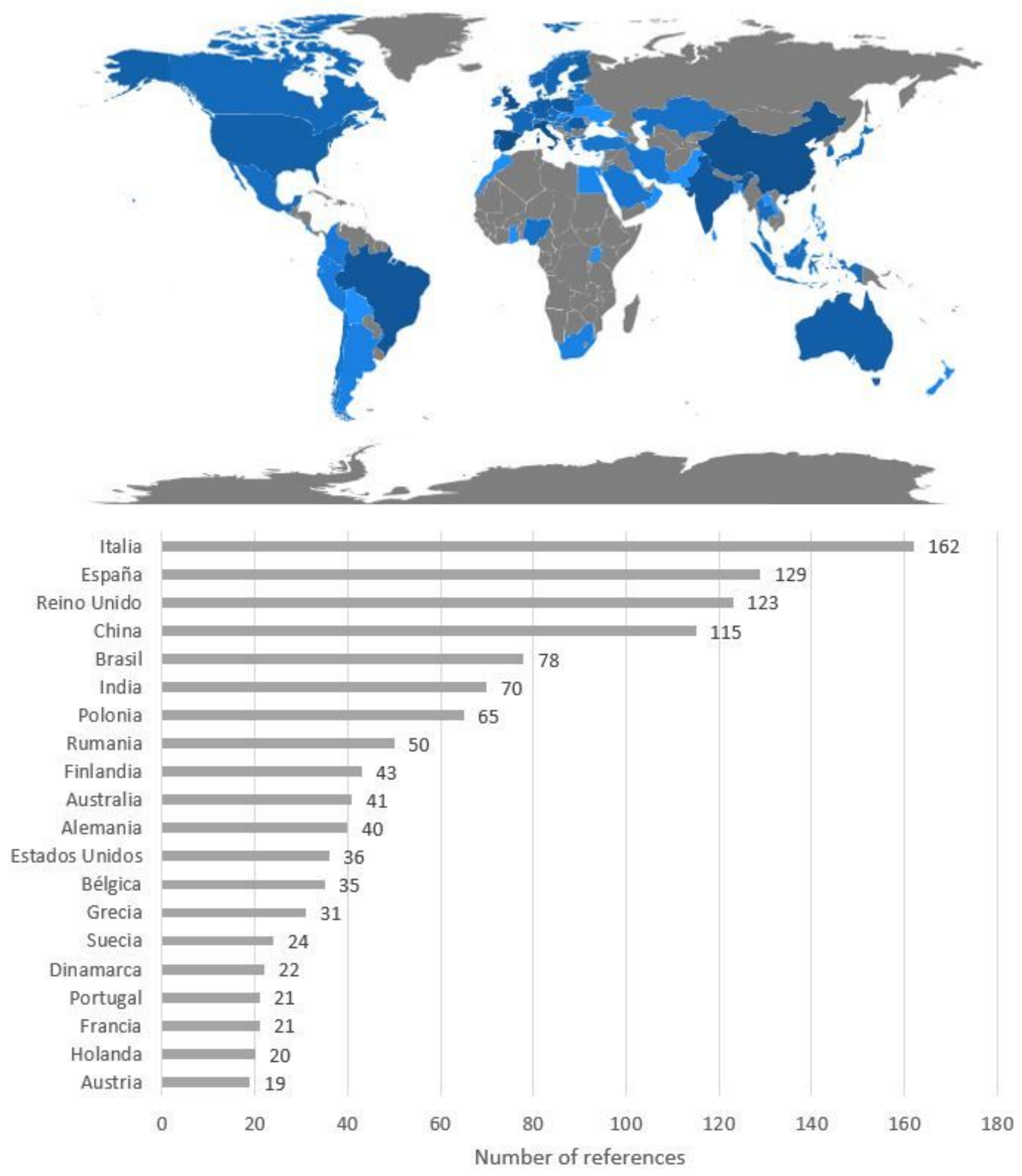

\section{Figure 3}

Top 20 countries with highest scientific production on Circular Economy (2007-2020) Source: Own elaboration based on Scopus database. Note: The designations employed and the presentation of the material on this map do not imply the expression of any opinion whatsoever on the part of Research Square concerning the legal status of any country, territory, city or area or of its authorities, or concerning the delimitation of its frontiers or boundaries. This map has been provided by the authors. 


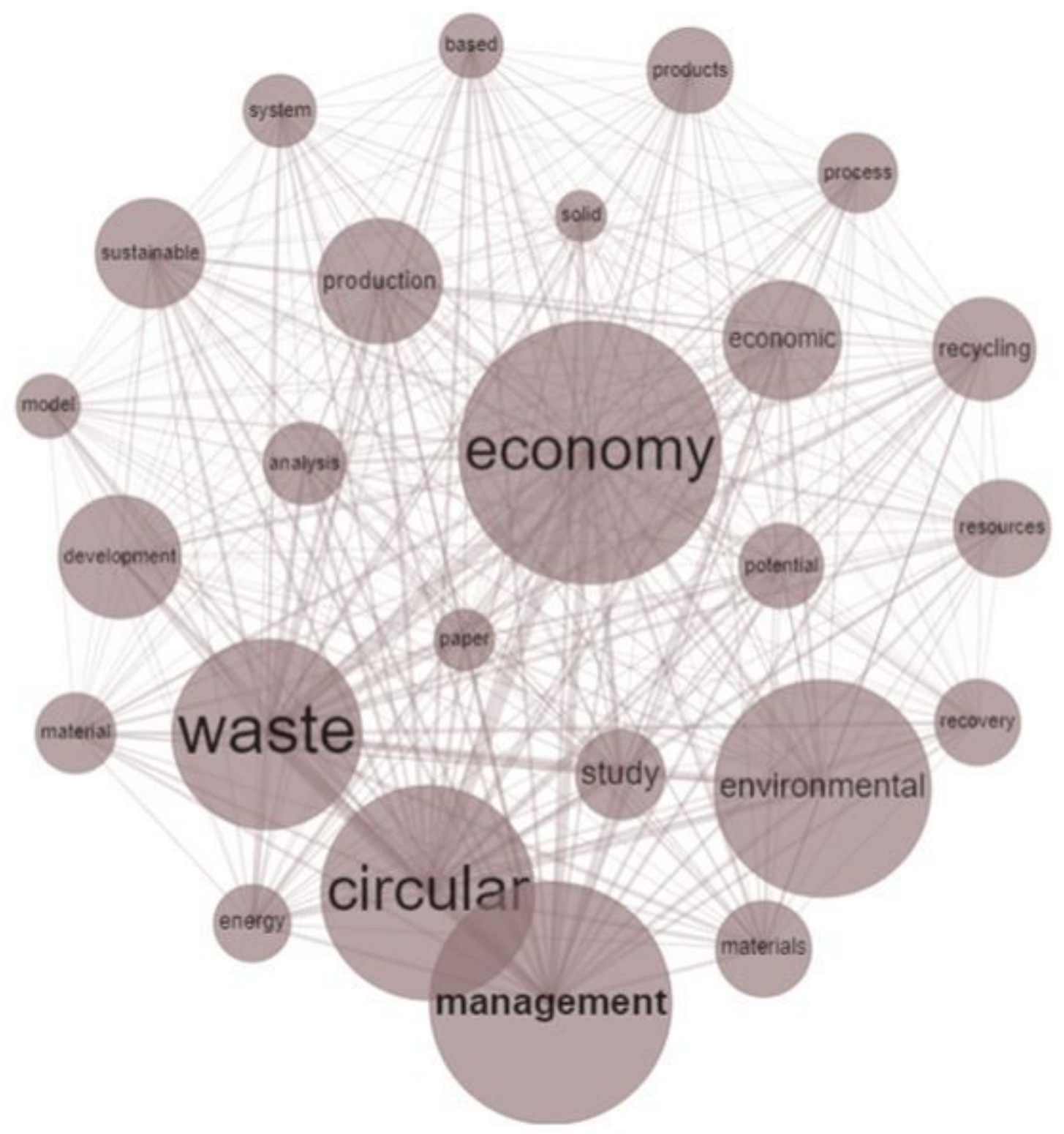

Figure 4

Research keywords in the period 2007-2020 Source: Own elaboration based on Scopus database. 


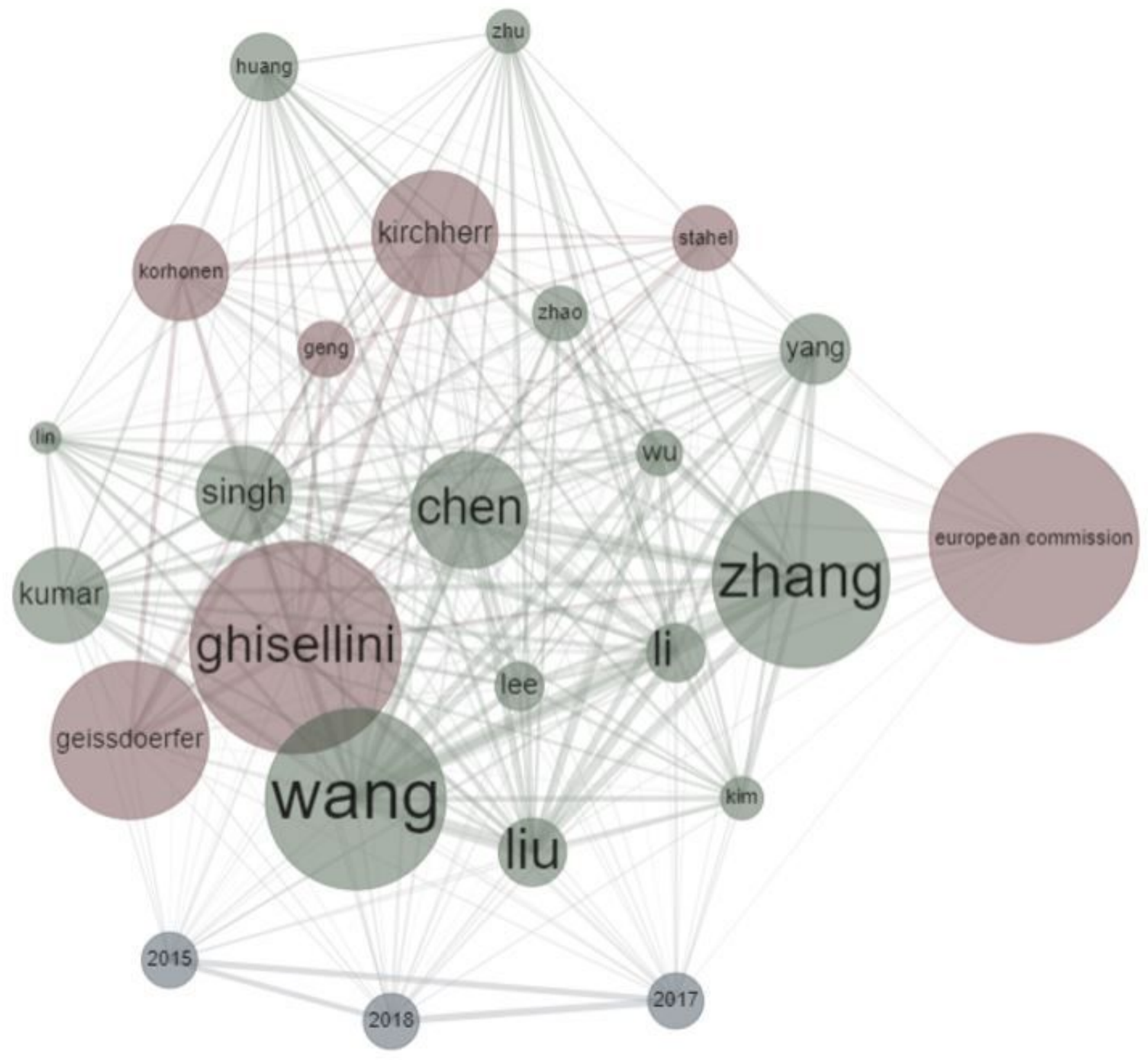

Figure 5

Network of co-cited authors Source: Own elaboration based on Scopus database. 